\title{
Global Initiative for Chronic Obstructive Lung Disease (GOLD) 20th Anniversary: a brief history of time
}

\author{
Roberto Rodriguez-Roisin ${ }^{1,2}$, Klaus F. Rabe ${ }^{3}$, Jørgen Vestbo ${ }^{4}$, Claus Vogelmeier $^{5}$ \\ and Alvar Agustí ${ }^{1,2,6,7}$, on behalf of all previous and current members of the \\ Science Committee and the Board of Directors of GOLD lgoldcopd.org/ \\ committees/l
}

Affiliations: ${ }^{1}$ University of Barcelona, Barcelona, Spain. ${ }^{2}$ Institut d'Investigacions Biomediques August Pi I Sunyer (IDIBAPS), Barcelona, Spain. ${ }^{3}$ LungenClinic Grosshansdorf and Christian Albrechts University Kiel, Kiel, Germany, Airway Research Centre North of the German Centre for Lung Research (DZL). "Division of Infection, Immunity and Respiratory Medicine, School of Biological Sciences, Manchester Academic Health Sciences Centre, University of Manchester, Manchester, UK. ${ }^{5}$ Department of Medicine, Pulmonary and Critical Care Medicine, University Medical Centre Giessen and Marburg, Philipps-Universität Marburg, Marburg, Germany, Member of the German Centre for Lung Research (DZL). ${ }^{6}$ Respiratory Institute, Hospital Clinic, Barcelona, Spain. ${ }^{7}$ Centro de Investigacion Biomedica en Red (CIBER) Enfermedades Respiratorias, Spain.

Correspondence: Alvar Agustí, Institut Respiratori, Hospital Clinic, Villarroel 170, Escala 3, Planta 5, 08036 Barcelona, Spain. E-mail: AAGUSTIAclinic.cat

@ERSpublications

A brief history of the Global Initiative for Chronic Obstructive Lung Disease (GOLD) on its 20th anniversary http://ow.ly/rcFE30bZVZ0

Cite this article as: Rodriguez-Roisin R, Rabe KF, Vestbo J, et al. Global Initiative for Chronic Obstructive Lung Disease (GOLD) 20th Anniversary: a brief history of time. Eur Respir J 2017; 50: 1700671 [https:// doi.org/10.1183/13993003.00671-2017].

As a community of people who care for and are interested in respiratory diseases, it is time that a major effort is focused on this disease... Writing and publishing guidelines is a futile effort if not implemented. A major task is improving the early diagnosis, management and prevention of COPD... As a society and community of respiratory physicians, COPD must be taken on as a major health problem.

Romain Pauwels [1]

The publication of the 2017 report of the Global Strategy for the Diagnosis, Management, and Prevention of Chronic Obstructive Lung Disease [2] marks the 20th anniversary of its birth back in 1997. The first Global Initiative for Chronic Obstructive Lung Disease (GOLD) Executive Summary was published in 2001 [3] and since then, GOLD updates the document annually and publishes a major report (revision) every five years. Thus, major reports have been published in 2006 [4], 2011 [5] and 2017 [6].

As the current chairman of the Board of Directors of GOLD, I (A. Agustí) was invited to write this Editorial to celebrate the 20th anniversary of GOLD. To do so, I asked Roberto Rodriguez-Roisin, as someone who can provide a first-hand account, to provide some memories of the "origins of GOLD" during the period 1997-2001, and Klaus Rabe, Jørgen Vestbo and Claus Vogelmeier to summarise the main differential features of the major revisions, which they chaired in 2006, 2011 and 2017, respectively. These concatenated sequence of events provides a unique, "brief history of time" for GOLD.

Received: March 302017 | Accepted: March 312017

Conflict of interest: Disclosures can be found alongside this article at erj.ersjournals.com

Copyright OERS 2017 
The origins of GOLD

Despite the fact that chronic obstructive pulmonary disease (COPD) was already considered a major cause of morbidity and mortality in the late 1990s, was the fourth leading cause of death worldwide, and further increases in its incidence and mortality were predicted for the following decades [7-9], a generalised nihilistic attitude towards the disease had arisen among healthcare providers. This was due to the relatively limited success of primary and secondary prevention, the prevailing view that COPD was largely a self-inflicted disease, and some disappointment with the limited treatment options available at that time. Although similar arguments could be used for many other highly prevalent disorders, such as cardiovascular and metabolic diseases, this however had not precluded significant basic and clinical research efforts, and the development of successful prevention and therapeutic strategies, for these other diseases.

With these concerns in mind, a number of COPD experts from around the world met in Brussels (Belgium) in January 1997 to explore the possibility of developing a global initiative for COPD (named Global Initiative for Chronic Lung Disease, GOLD, 2 years later). The late Romain Pauwels (1943-2005) [10], Professor of Medicine at the University Hospital of Ghent (Belgium), along with the leadership of the US National Institutes of Health (NIH) (Claude Lenfant [11] and Suzanne Hurd [7]) and the World Health Organization (WHO) (Nikolai Khaltaev), served as Chairs. Participants agreed that the project was timely and important, and recommended the establishment of a panel with expertise on a wide variety of COPD-related topics, to prepare an evidence-based report on the diagnosis, management, and prevention of COPD. Individuals from several regions of the world were asked to serve on the Expert Panel, which included health professionals in the areas of respiratory medicine, epidemiology, pathology, socioeconomics, public health and health education. The first step towards developing the workshop report was to review the multiple COPD guidelines already published and summarise their similarities and differences. Where agreement existed, the Expert Panel drew from these documents for use in the report. Where major differences existed, the panel agreed to examine the scientific evidence to reach an independent conclusion. In April 1998, the National Heart, Lung and Blood Institute (NHLBI) and WHO co-sponsored a workshop to begin the development of the future GOLD Report. Workshop participants were divided into three groups with their respective chairs: "Definition and natural history", chaired by Sonia Buist, "Pathophysiology, risk factors, diagnosis, and classification of severity", chaired by Leonardo Fabbri and "Disease management", chaired by R Pauwels. The panel agreed that clinical recommendations should ideally be based on scientific evidence or alternatively, be clearly labelled as "expert opinion". In September 1998, members reviewed a variety of evidence tables and chose to assign various levels of evidence to statements, using the system developed by the NHLBI, and more specifically assigned management recommendations where appropriate. The panel met again in May and September 1999 and May 2000, in conjunction with meetings of the American Thoracic Society (ATS) and the European Respiratory Society (ERS). Symposia were held at these meetings to present the developing programme and to solicit opinions and comments. The meeting in May 2000 was the final consensus workshop. After this workshop, the document was submitted for review to international experts and medical societies interested in the management of COPD. The reviewers' comments were incorporated, as appropriate, into the final document (i.e. the future GOLD 2001 Report) by the Chair, in cooperation with members of the Expert Panel. Prior to its release for publication, the report was reviewed by the NIH and WHO. A workshop was held in September 2000 to begin the implementation of the GOLD programme. The workshop report was also used as the basis for the development of more concise, practical documents. Thus, an executive summary was published in one of the most prestigious respiratory journals [3], and an $\mathrm{NIH}$ publication and a pocket guide for physicians and nurses, as well as a small guide for patients and their families were produced (www.goldcopd.org).

This first GOLD 2001 Report [3] had a number of salient features. First, it proposed a new classification of COPD severity, based on spirometry and arterial blood gas disturbances (figure 1), which was regarded at that time as a pragmatic approach fit for practical implementation. Second, a GOLD Stage 0 (or "At Risk") category, defined by normal spirometry in the presence of chronic cough and sputum production, was introduced as an opportunity for early identification and intervention in individuals at risk. Although later iterations of the GOLD document deleted this concept, debate on the relevance of chronic respiratory symptoms in individuals with normal spirometry continues to date [12].

Finally, on a more logistic and legal side, it is most appropriate to recall here that GOLD, Inc. was implemented (and still is today) as a non-profit, tax-exempt, non-stock corporation. The original (and current) main objective of this entity was (and is) to promote an independent global network of professional health organisations, patient organisations/foundations, government agencies, health care providers and individuals with an interest in COPD research, patient care, and health promotion/ disease prevention to improve: (1) awareness and evidence-based educational resources about COPD for 


\begin{tabular}{|ll} 
2001: Classification of COPD by severity \\
\hline Stage & \multicolumn{1}{c}{ Characteristics } \\
\hline 0: At risk & Normal spirometry \\
I: Mild COPD & Chronic symptoms (cough, sputum production) \\
& $\mathrm{FEV} 1 / \mathrm{FVC}<70 \%$ \\
& $\mathrm{FEV} 1>80 \%$ predicted \\
& With or without chronic symptoms \\
& (cough, sputum production) \\
II: Moderate COPD & $\mathrm{FEV} 1 / \mathrm{FVC}<70 \%$ \\
& $30 \%<\mathrm{FEV} 1<80 \%$ predicted \\
& (IIA: $50 \%<\mathrm{FEV} 1<80 \%$ predicted) \\
& (IIB: $30 \%<\mathrm{FEV} 1<50 \%$ predicted) \\
& With or without chronic symptoms \\
& (cough, sputum production, dyspnoea) \\
& FEV $1 /$ FVC $<70 \%$ \\
& FEV $1<30 \%$ predicted, or the presence of \\
III: Severe COPDiratory failure, \# or clinical signs of right & heart failure
\end{tabular}

\# Respiratory failure: $\mathrm{PaO}_{2}<8.0 \mathrm{kPa}(60 \mathrm{mmHg})$ with or without $\mathrm{PaCO}_{2}>6.7 \mathrm{kPa}(50 \mathrm{mmHg}$ ) while breathing air at sea level.
2006: Spirometric classification of chronic obstructive pulmonary disease severity based on post-bronchodilator FEV 1

\begin{tabular}{|c|c|}
\hline Stage I: Mild & $\begin{array}{l}\mathrm{FEV} 1 / \mathrm{FVC}<0.70 \\
\mathrm{FEV} 1 \geqslant 80 \% \text { predicted }\end{array}$ \\
\hline Stage II: Moderate & $\begin{array}{l}\mathrm{FEV}_{1} / \mathrm{FVC}<0.70 \\
50 \% \leqslant \mathrm{FEV}_{1}<80 \% \text { predicted }\end{array}$ \\
\hline Stage III: Severe & $\begin{array}{l}\mathrm{FEV}_{1} / \mathrm{FVC}<0.70 \\
30 \% \leqslant \mathrm{FEV}_{1}<50 \% \text { predicted }\end{array}$ \\
\hline Stage IV: Very severe & $\begin{array}{l}\mathrm{FEV}_{1} / \mathrm{FVC}<0.70 \\
\mathrm{FEV} 1<30 \% \text { predicted or } \mathrm{FEV}_{1}<50 \% \\
\text { predicted plus chronic respiratory } \\
\text { failurefl }\end{array}$ \\
\hline
\end{tabular}

I Respiratory failure: arterial partial pressure of oxygen $\left(\mathrm{PaO}_{2}\right)$ $<8.0 \mathrm{kPa}\left(60 \mathrm{mmHg}\right.$ ) with or without arterial partial pressure of $\mathrm{CO}_{2}$ $\left(\mathrm{PaCO}_{2}\right)>6.7 \mathrm{kPa}(50 \mathrm{mmHg})$ while breathing air at sea level.
2011: Combined COPD assessment. When assessing risk, choose the highest risk according to GOLD spirometric grade or exacerbation history.

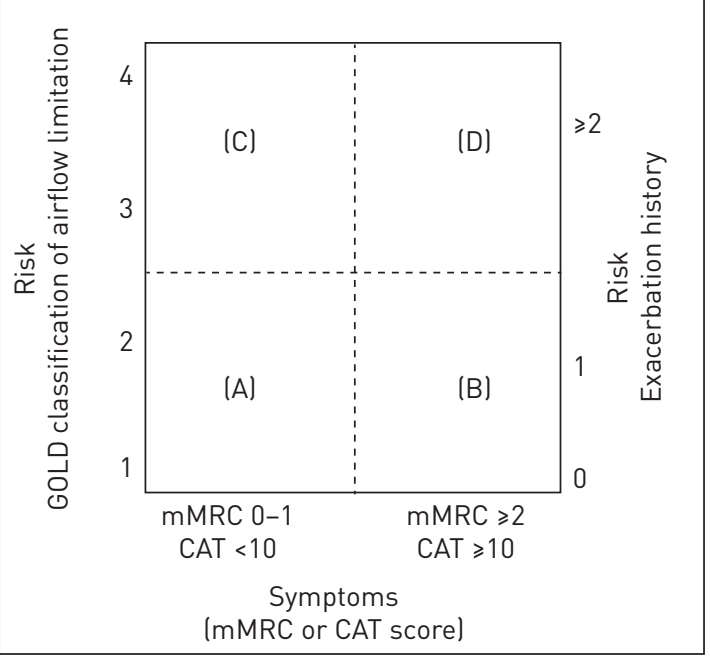

2017: The refined $A B C D$ assessment tool

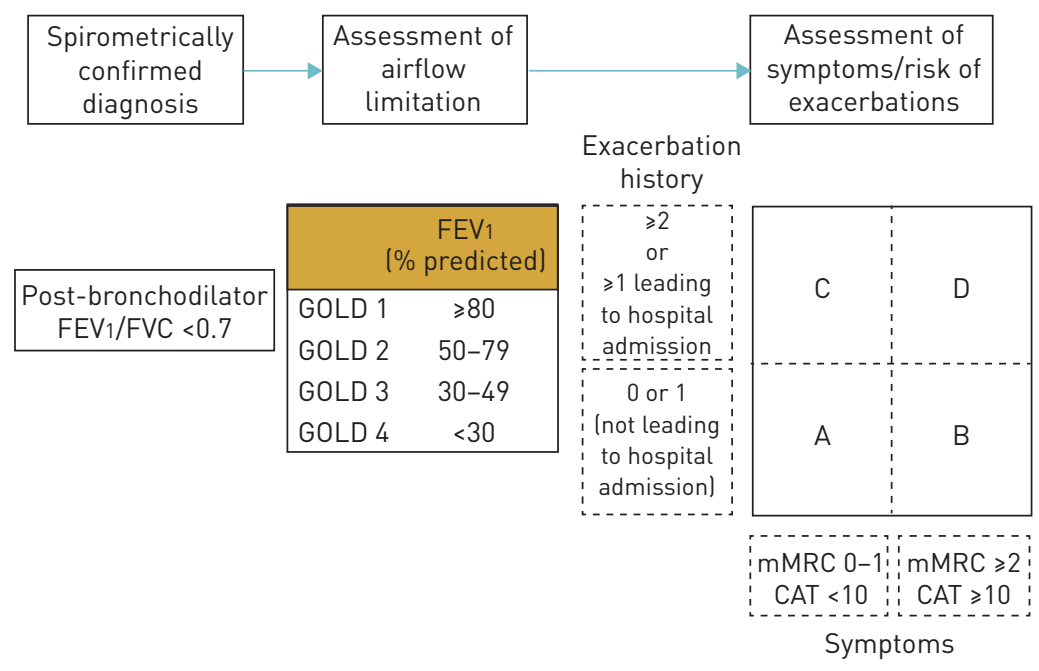

FIGURE 1 COPD assessment and classification as proposed by GOLD 2001, 2006, 2011 and 2017 Reports. For further explanations, see text. GOLD: Global Initiative for Chronic Obstructive Lung Disease; mMRC: modified Medical Research Council; CAT: COPD Assessment Test. Reproduced from [3-6], with permission from the publishers.

health professionals and health authorities, and the general public; (2) the prevention, diagnosis and management of COPD; and (3) foster the necessary research to fill the existing gaps in the available scientific evidence.

\section{GOLD 2006}

Members of the original GOLD panel soon realised that the emphasis of the initial 2001 report on public health had to be revisited, ironically, because of the huge success of the initiative. Thus, after the release of the GOLD 2001 Report [3], a scientific committee was formed and charged with keeping the documents up-to-date by reviewing published research, evaluating the impact of this research on the management recommendations in GOLD documents, and posting yearly updates of these documents on the GOLD website [13]. With the implementation of the "GOLD National Leaders (GNLs) initiative", several novel investigations and methods of dissemination commenced at national and regional levels worldwide. The general opinion was that the particular strength of the GOLD document was the regular and standardised 
updating processes based on the available literature, a process that would have never occurred without the strong leadership and discipline of Suzanne Hurd, the true heroine of this initiative during this phase [13]. The new GOLD Executive Summary was published in the American Journal of Respiratory and Critical Care Medicine in 2007 [4] and generated more than 2000 citations according to the Web of Science, making it one of the most cited and influential papers ever for the journal.

The GOLD 2006 Report [4] introduced some significant changes, including the following: (1) for the first time, the notion that COPD was also characterised by significant extra-pulmonary effects and important comorbidities [14, 15] was acknowledged. (2) The apparently innocent statement "preventable and treatable" was incorporated following the ATS/ERS recommendations [16] to present a positive outlook for patients and encourage the health care community to take a more active role in developing programmes for COPD prevention. (3) The spirometric classification of the severity of COPD included four stages (now referred to as grades) with the exclusion of the "GOLD Stage 0, At Risk," which appeared in the GOLD 2001 Report, because of incomplete evidence that individuals who meet the definition of "at risk" (chronic cough and sputum production only with normal spirometry) necessarily progress to stage I [17]. This decision was fiercely debated, although the importance of the public health message that chronic cough and sputum are abnormal remained unchanged, and the fact that their presence should trigger a search for underlying causes was maintained. (4) The spirometric classification of severity continued to recommend the use of the fixed ratio post-bronchodilator $\mathrm{FEV} 1 / \mathrm{FVC}<0.7$ to define airflow limitation; however, it was acknowledged that using the fixed FEV1/FVC ratio was particularly problematic in elderly patients with milder disease, because the normal process of ageing affects lung volumes. (5) Cigarette smoking was highlighted as the most common risk factor for COPD; however, emphasis was placed on other risk factors, including occupational dust and chemicals, and indoor air pollution from biomass cooking and heating in poorly ventilated dwellings, the latter especially so, among women in developing countries [4]. (6) Implementation efforts related to GOLD were also considered somewhat lagging behind in a precise review of the current literature, and a specific section on COPD implementation programmes and issues for clinical practice was included.

\section{GOLD 2011}

The 2011 GOLD Report [5] represented a significant detour from previous documents for the following reasons: (1) The general consensus was that there was a strong need to move away from the GOLD staging system used up to that point in time, and there was evidence of many important aspects besides FEV1. Furthermore, combined indices, such as the BODE (Body-mass index, airflow Obstruction, Dyspnoea, and Exercise capacity [18]) and the ADO (Age, Dyspnoea, and airflow Obstruction [19]) showed much better prognostic value than FEV1 alone. In addition, there was a growing understanding that the choice of treatment was not heavily dependent on the level of lung function. Moreover, the existence of a frequent exacerbator phenotype $[20,21]$ had been more or less broadly accepted. The Scientific Committee had long and often heated discussions on a new model for the categorisation of COPD, and many draft figures were created. Eventually, the document prioritised a categorisation that was aimed at guiding management rather than providing better prognostic value than FEV1. In summary, the ABCD classification square was created (figure 1), highlighting two features of the disease that can be best targeted by treatment, symptoms and exacerbations. The importance of a standardised assessment of symptoms was proposed $(i$. e. the COPD Assessment Test (CAT) of respiratory quality of life and/or the modified Medical Research Council questionnaire on breathlessness). (2) A new chapter on comorbidities was introduced, thereby stressing that assessment and management of comorbidities was a crucial feature of managing the patient with COPD. (3) The chapter on management of stable COPD was divided, so that the description and evidence for treatment options were provided in one chapter, whereas the recommendations for the best use of these options in clinical practice were provided in a different chapter. (4) A recommendation for regular physical activity, in addition to pulmonary rehabilitation was included. (5) Finally, these changes were incorporated in an abbreviated, but complete document, as it was never the aim for GOLD to be a COPD textbook, as was evident in the two previous GOLD reports.

The ABCD proposal was relatively well received, but was criticised for: (1) being too complicated for non-respiratory health professionals - a little surprising, given the complexity of e.g. cardiovascular risk scoring that general practitioners use every day; (2) the fact that the prognosis for Group B was worse than that for Group $C$ [22]. Yet, the aim of the $A B C D$ proposal was never to improve prognosis, but aid management [5]. Admittedly though, the weakest point in the ABCD classification was likely the inclusion of the FEV 1 grade in the assessment of the risk of exacerbations, as lung function on its own is a relatively weak predictor of exacerbations [21]. Thus, the classification might have inadvertently classified too many patients as high-risk, despite a low risk of exacerbations. Despite these limitations, the move from GOLD stages 1-4 based on the FEV1 only [4] to a multidimensional approach (ABCD) [5] was important, as it 
emphasised that classifying COPD on a more holistic scenario should facilitate more precise management of the individual patient [23].

\section{GOLD 2017}

The major revision of GOLD 2016 was presented in Philadelphia (USA) on November 16, 2016. To avoid being outdated from the very beginning, this document is referred to as the GOLD 2017 Report [6]. Similarly, to achieve maximal global dissemination, for the first time, the GOLD 2017 Executive Summary has been published simultaneously in four journals that cover North America [24], Latin America [25], Europe [6] and the Asia-Pacific regions [26], respectively. Although all chapters underwent major revision, the most important changes included the introduction of algorithms for pharmacological treatments and a refinement of the "ABCD" assessment system as follows: (1) the 2011 ABCD assessment tool [5] had been considered a major step forward, from the old spirometric grading system [3, 4]; however, several limitations were also identified. Firstly, it performed no better than the spirometric grades for mortality prediction or other important health outcomes [27-29]. Furthermore, patients could be categorised in Groups C and D under various circumstances, based on lung function, exacerbation history, or both, which led to confusion [30]. Because of this, a refined ABCD system that separated spirometric grades from the "old" four quadrants was proposed, and the recommendations for drug treatment are now based exclusively on symptoms and history of exacerbation, and not solely on FEV1 (figure 1). Nevertheless, if there is a major discrepancy between perceived symptoms and airflow limitation severity, a more detailed evaluation is warranted [2]. (2) For the first time, a dynamic algorithm (up or down) was proposed to guide practising physicians in tailoring pharmacological treatment to the needs of the individual patient [2]. The GOLD Scientific Committee is fully aware however, that treatment escalation has not been systematically tested. In particular, the precise role of triple therapy (long-acting anticholinergics, plus long-acting $\beta$-agonists, plus inhaled corticosteroids) remains yet to be established, and trials of de-escalation are also limited to inhaled corticosteroids [31-33].

\section{Conclusions}

The COPD landscape has undergone very significant changes over the last 20 years. We now understand the heterogeneity and complexity of the disease much better, and now have novel pharmacological and non-pharmacological options to ameliorate the suffering of COPD patients [2]. Many individuals working in primary, secondary and tertiary care centres, as well as in academy, industry and professional societies have no doubt, contributed to these developments. GOLD however, has been a key blender of these changes and above all, a think tank that continuously produces inspiring proposals on COPD. Accordingly, the authors of this Editorial wish to pay special tribute to R. Pauwels [10], C. Lenfant [11] and S. Hurd [7], who were the catalysts and backbone of the GOLD project since its inception. Likewise, they also wish to acknowledge the enthusiasm and dedication over these 20 years, of the many members of the GOLD Scientific Committee and GOLD Board of Directors, too numerous to be mentioned individually (see www.goldcopd.org), but indispensable collectively. Without them all, this brief history of GOLD would have never happened.

\section{Acknowledgements}

Authors thank Rebecca Dekker, current Program Director of GOLD and Global Initiative for Asthma, for her current daily work in support of GOLD activities.

\section{References}

1 Pauwels R. Global initiative for chronic obstructive lung diseases (GOLD): time to act. Eur Respir J 2001; 18: 901-902.

2 Vogelmeier C, Agusti A, Anzueto A, et al. Global strategy for the diagnosis, management, and prevention of Chronic Obstructive Pulmonary Disease (2017 Report) 2017. http://goldcopd.org/ gold-2017-global-strategy-diagnosis-management-prevention-copd/

3 Pauwels RA, Buist AS, Calverley PM, et al. Global strategy for the diagnosis, management, and prevention of chronic obstructive pulmonary disease. NHLBI/WHO Global Initiative for Chronic Obstructive Lung Disease (GOLD) Workshop summary. Am J Respir Crit Care Med 2001; 163: 1256-1276.

4 Rabe KF, Hurd S, Anzueto A, et al. Global strategy for the diagnosis, management, and prevention of chronic obstructive pulmonary disease: GOLD executive summary. Am J Respir Crit Care Med 2007; 176: 532-555.

5 Vestbo J, Hurd SS, Agustí A, et al. Global strategy for the diagnosis, management, and prevention of chronic obstructive pulmonary disease: GOLD executive summary. Am J Respir Crit Care Med 2013; 187: $347-365$.

6 Vogelmeier CF, Criner GJ, Martinez FJ, et al. Global Strategy for the Diagnosis, Management, and Prevention of Chronic Obstructive Lung Disease 2017 Report. GOLD Executive Summary. Eur Respir J 2017; 49 : 1700214.

7 Hurd S. The impact of COPD on lung health worldwide: epidemiology and incidence. Chest 2000; 117: Suppl. 2, $1 \mathrm{~S}-4 \mathrm{~S}$.

8 Murray CJL, Lopez AD. Mortality by cause for eight regions of the world: global burden of disease study. Lancet 1997; 349: 1269-1276.

9 Murray CJ, Lopez AD. Regional patterns of disability-free life expectancy and disability-adjusted life expectancy: global Burden of Disease Study. Lancet 1997; 349: 1347-1352. 
10 Bousquet J, Fabbri LM, O’Byrne P, et al. In memoriam Romain Pauwels. Eur Respir J 2005; 25: $585-586$.

11 Roccella EJ. Giants in Chest Medicine: Claude Lenfant, MD. Chest 2017; 151: 11-13.

12 Rodriguez-Roisin R, Han MK, Vestbo J, et al. Chronic respiratory symptoms with normal spirometry. A reliable clinical entity? Am J Respir Crit Care Med 2017; 195: 17-22.

13 Fabbri LM, Hurd SS. Global Strategy for the Diagnosis, Management and Prevention of COPD: 2003 update. Eur Respir J 2003; 22: 1-2.

14 Agustí AG, Noguera A, Sauleda J, et al. Systemic effects of chronic obstructive pulmonary disease. Eur Respir J $2003 ; 21: 347-360$.

15 Wouters EF, Creutzberg EC, Schols AM. Systemic effects in COPD. Chest 2002; 121: Suppl. 5, 127S-130S

16 Celli BR, MacNee W, Agusti AG, et al. Standards for the diagnosis and treatment of patients with COPD: a summary of the ATS/ERS position paper. Eur Respir J 2004; 23: 932-946.

17 Vestbo J, Lange P. Can GOLD Stage 0 provide information of prognostic value in chronic obstructive pulmonary disease? Am J Respir Crit Care Med 2002; 166: 329-332.

18 Celli BR, Cote CG, Marin JM, et al. The Body-Mass Index, Airflow Obstruction, Dyspnea, and Exercise Capacity Index in chronic obstructive pulmonary disease. N Engl J Med 2004; 350: 1005-1012.

19 Puhan MA, Garcia-Aymerich J, Frey M, et al. Expansion of the prognostic assessment of patients with chronic obstructive pulmonary disease: the updated BODE index and the ADO index. Lancet 2009; 374: 704-711.

20 Soler-Cataluña JJ, Rodriguez-Roisin R. Frequent chronic obstructive pulmonary disease exacerbators: how much real, how much fictitious? COPD 2010; 7: 276-284.

21 Hurst JR, Vestbo J, Anzueto A, et al. Susceptibility to exacerbation in chronic obstructive pulmonary disease. N Engl J Med 2010; 363: 1128-1138.

22 Agusti A, Hurd S, Jones P, et al. Frequently asked questions (FAQs) about the GOLD 2011 assessment proposal of COPD. Eur Respir J 2013; 42: 1391-1401.

23 Agusti A. The path to personalized medicine in COPD. Thorax 2014; 69: 857-864.

24 Vogelmeier CF, Criner GJ, Martinez FJ, et al. Global Strategy for the Diagnosis, Management, and Prevention of Chronic Obstructive Lung Disease 2017 Report: GOLD Executive Summary. Am J Respir Crit Care Med 2017; 195: $557-582$.

25 Vogelmeier CF, Criner GJ, Martinez FJ, et al. Global Strategy for the Diagnosis, Management, and Prevention of Chronic Obstructive Lung Disease 2017 Report: GOLD Executive Summary. Arch Bronconeumol 2017; 53: $128-149$.

26 Vogelmeier CF, Criner GJ, Martinez FJ, et al. Global Strategy for the Diagnosis, Management and Prevention of Chronic Obstructive Lung Disease 2017 Report: GOLD Executive Summary. Respirology 2017; 22: 575-601.

27 Soriano JB, Lamprecht B, Ramírez AS, et al. Mortality prediction in chronic obstructive pulmonary disease comparing the GOLD 2007 and 2011 staging systems: a pooled analysis of individual patient data. Lancet Respir Med 2015; 3: 443-450.

28 Goossens LM, Leimer I, Metzdorf N, et al. Does the 2013 GOLD classification improve the ability to predict lung function decline, exacerbations and mortality: a post-hoc analysis of the 4-year UPLIFT trial. BMC Pulm Med 2014; 14: 163.

29 Kim J, Yoon HI, Oh YM, et al. Lung function decline rates according to GOLD group in patients with chronic obstructive pulmonary disease. Int J Chron Obstruct Pulmon Dis 2015; 10: 1819-1827.

30 Han MK, Mullerova H, Curran-Everett D, et al. GOLD 2011 disease severity classification in COPDGene: a prospective cohort study. Lancet Respir Med 2013; 1: 43-50.

31 Suissa S, Rossi A. Weaning from inhaled corticosteroids in COPD: the evidence. Eur Respir J 2015; 46 : $1232-1235$.

32 Magnussen H, Disse B, Rodriguez-Roisin R, et al. Withdrawal of inhaled glucocorticoids and exacerbations of COPD. N Engl J Med 2014; 371: 1285-1294.

33 Watz H, Tetzlaff K, Wouters EF, et al. Blood eosinophil count and exacerbations in severe chronic obstructive pulmonary disease after withdrawal of inhaled corticosteroids: a post-hoc analysis of the WISDOM trial. Lancet Respir Med 2016; 4: 390-398. 